\title{
Analyses of the oligopeptide transporter gene family in poplar and grape
}

\author{
Jun $\mathrm{CaO}^{1,2}$, Jinling Huang ${ }^{3}$, Yongping $\mathrm{Yang}^{1}$ and Xiangyang $\mathrm{Hu}^{{ }^{*}}$
}

\begin{abstract}
Background: Oligopeptide transporters (OPTs) are a group of membrane-localized proteins that have a broad range of substrate transport capabilities and that are thought to contribute to many biological processes. The OPT proteins belong to a small gene family in plants, which includes about 25 members in Arabidopsis and rice. However, no comprehensive study incorporating phylogeny, chromosomal location, gene structure, expression profiling, functional divergence and selective pressure analysis has been reported thus far for Populus and Vitis.

Results: In the present study, a comprehensive analysis of the OPT gene family in Populus (P. trichocarpa) and Vitis ( $V$. vinifera) was performed. A total of 20 and 18 full-length OPT genes have been identified in Populus and Vitis, respectively. Phylogenetic analyses indicate that these OPT genes consist of two classes that can be further subdivided into 11 groups. Gene structures are considerably conserved among the groups. The distribution of OPT genes was found to be non-random across chromosomes. A high proportion of the genes are preferentially clustered, indicating that tandem duplications may have contributed significantly to the expansion of the OPT gene family. Expression patterns based on our analyses of microarray data suggest that many OPT genes may be important in stress response and functional development of plants. Further analyses of functional divergence and adaptive evolution show that, while purifying selection may have been the main force driving the evolution of the OPTs, some of critical sites responsible for the functional divergence may have been under positive selection.

Conclusions: Overall, the data obtained from our investigation contribute to a better understanding of the complexity of the Populus and Vitis OPT gene family and of the function and evolution of the OPT gene family in higher plants.
\end{abstract}

\section{Background}

Substrate transport is vital for all living organisms, and many transporters play important roles in this process. More than 600 transporter families are currently documented in the Transporter Classification Database (TCDB) [1,2]. These protein families are further classed into seven subclasses (channels/pores, electrochemical potential-driver transporters, primary active transporters, group translocators, transport electron carriers, accessory factors involved in transport, and incompletely characterized transport systems). In general, they have specific localizations within the cell and are specialized to carry different compounds, including nitrate,

\footnotetext{
* Correspondence: huxiangyang@mail.kib.ac.cn

${ }^{1}$ Key Laboratory of Biodiversity and Biogeography, Kunming Institute of Botany, Institute of Tibet Plateau Research at Kunming, Chinese Academy of Sciences, Kunming, 650204, China

Full list of author information is available at the end of the article
}

phosphate, sucrose, amino acids, peptides, hormones or metals.

The peptide transporter family consists of electrochemical potential-driven transporters that catalyze uptake of their solutes by a cation-solute symport mechanism [3]. In plants, peptide transporters can be classified into three distinct groups based on sequence similarity and mechanism of action, namely the ATP-binding cassette family, the peptide transporter family and the oligopeptide transporter (OPT) family. The plant ATP-binding cassette proteins use the energy generated by ATP hydrolysis to drive the transport of substrates such as peptides, metal chelates or glutathione conjugates [4]. The peptide transporters have been shown to transport nitrate, and di- and tripeptides [5,6]. Members of the OPT family were first characterized in yeast $[7,8]$, and since then they have also been found in archaea, bacteria and plants. Phylogenetic analyses of plant OPT
C Biomed Central

() 2011 Cao et al; licensee BioMed Central Ltd. This is an Open Access article distributed under the terms of the Creative Commons Attribution License (http://creativecommons.org/licenses/by/2.0), which permits unrestricted use, distribution, and reproduction in any medium, provided the original work is properly cited. 
members have revealed two distant clades: the yellow stripe-like (YSL) proteins and the OPTs. The YSL transporters are involved in metal homeostasis through the translocation of metal-chelates [9-16]. The OPT proteins likely do not have a common biological function and may be involved in four different processes: long-distance metal distribution [17], nitrogen mobilization [18-21], heavy metal sequestration [19,21-23], and glutathione transport $[19,21,22,24]$. These processes may play a role in plant growth and development [see [25] for review].

Structurally, OPT proteins are predicted to have about 16 transmembrane strands (TMS). Through detailed bioinformatic analyses of these transporters, Gomolplitinant and Saier [26] suggested that the 16-TMS proteins might have arisen from a 2-TMS precursor-encoding genetic element that was subject to three sequential duplication events. Since the transporters are predicted to function in peptide uptake, the expansion or fusion of the TMS might make excellent physiological sense in evolution.

The structural features or expression profiles of some OPT homologs have been partially described in Arabidopsis [18] and rice [23]. Hoverer, there is much less information about this family in woody plant species such as Populus trichocarpa (poplar) and Vitis vinifera (grape). In the present study, we performed a genome- wide identification of OPT family genes in Populus and Vitis. Detailed analyses including sequence phylogeny, gene organization, conserved motifs, expression profiling, functional divergence and adaptive evolution were performed. Our results should provide a framework for further functional investigations on these genes.

\section{Results and Discussion}

Identification of the OPT gene family in Populus and Vitis To identify members of the OPT gene family in Populus and Vitis, we first searched relevant databases using the corresponding Arabidopsis and rice OPT protein sequences as queries. Additional searches were also performed based on keyword querying. The Populus and Vitis sequences returned from such searches were confirmed as encoding OPTs using the CDD (Conserved Domain Database) $[27,28]$ and Pfam http://pfam.sanger. ac.uk/ databases. As a result of this process, we identified 20 OPT genes in Poplar (Table 1) and 18 in Vitis (Table 2). The number of OPT genes present in the Arabidopsis and rice genomes was reported to be 12 and 25, respectively $[18,23]$. The OPT genes in Vitis and Populus encode highly hydrophobic polypeptides (grand average hydrophobicities of 0.329 to 0.628 ) ranging from 372 to 760 amino acids in length, with predicted pIs ranging from 5.45 to 9.44 . The polypeptides were also predicted to contain from 8-16 transmembrane helices

Table 1 Oligopeptide transporter genes identified in Populus

\begin{tabular}{|c|c|c|c|c|c|c|c|}
\hline Gene name & Gene ID & Genomic position & Protein Length & pl & GRAVY* & No. of TMHs** & PSORT predictions ${ }^{* * *}$ \\
\hline PtOPT1 & 7458477 & LG_Vl:414929..418505(-) & 744 & 9.14 & 0.382 & 16 & P: 13 \\
\hline PtOPT2 & 7476446 & LG_V:6874384..6878065(+) & 747 & 8.45 & 0.43 & 12 & $P: 11, N: 1, C: 1$ \\
\hline PtOPT3 & 7461839 & LG_II:7990890..7994069(+) & 724 & 9.07 & 0.496 & 12 & $P: 8, V: 3, E . R:: 2$ \\
\hline PtOPT4 & 7469682 & LG_IV:5289927..5295373(+) & 752 & 9 & 0.459 & 16 & $P: 14$ \\
\hline PtOPT5 & 7474080 & LG_XVI:102654..100307(-) & 661 & 9.44 & 0.381 & 14 & P: 9, E.R.: 3, Ch: 2 \\
\hline PtOPT6 & 7485123 & LG_l:30102965..30106100(+) & 756 & 8.92 & 0.396 & 16 & $P: 12, V: 1$ \\
\hline PtOPT7 & 7485120 & LG_l:36933302..36936452(+) & 724 & 9.31 & 0.406 & 14 & $P: 9, V: 3, E . R:: 2$ \\
\hline PtOPT8 & 7472512 & LG_XVI:5869..8859(+) & 748 & 9.07 & 0.411 & 12 & P: 10, E.R.: 4 \\
\hline PtOPT9 & 7496418 & LG_XII:2251759..2269550(+) & 723 & 8.93 & 0.391 & 14 & P: 9, V: 2, E.R.: 2 \\
\hline PtOPT10 & 7456066 & LG_III:8705285..8709320(+) & 750 & 8.06 & 0.411 & 14 & P: 8, G: 3, E.R.: 2 \\
\hline PtOPT11 & 7465336 & LG_III:13357805..13361193(+) & 760 & 5.57 & 0.392 & 14 & $P: 9, C: 3, M: 1$ \\
\hline PtYSL1 & 7467032 & LG_I:5980774..5978118(-) & 662 & 9.13 & 0.596 & 14 & $P: 8, G: 3, V: 2$ \\
\hline PtYSL2 & 7477824 & LG_l:5980705..6181638(-) & 652 & 9.23 & 0.526 & 14 & $P: 10, E . R:: 2, V: 1$ \\
\hline PtYSL3 & 7464319 & LG_XII:2602881..2601171(-) & 625 & 9.29 & 0.615 & 11 & P: 6, Ch: 4, E.R:: 3 \\
\hline PtYSL4 & 7492083 & LG_V:2731980..2734897(+) & 665 & 9.16 & 0.524 & 15 & $\mathrm{~V}: 8, \mathrm{P}: 3, \mathrm{G}: 2$ \\
\hline PtYSL5 & 7494364 & LG_IV:2622178..2624820(-) & 687 & 8.86 & 0.426 & 12 & $P: 10, G: 2, V: 1$ \\
\hline PtYSL6 & 7495797 & LG_l:24263574..24268468(+) & 669 & 5.54 & 0.628 & 13 & $P: 8, V: 4, G: 2$ \\
\hline PtYSL7 & 7470849 & scaffold_184:5062..8519(+) & 668 & 9.13 & 0.496 & 12 & $P: 7, V: 4, G: 3$ \\
\hline PtYSL8 & 7470829 & scaffold_184:6206..5052(-) & 372 & 9.09 & 0.565 & 8 & G:5, P:4.5, G:4.5, Ch:2, N:1, V:1 \\
\hline PtYSL9 & 7483743 & scaffold_5835:114..2350(+) & 582 & 8.89 & 0.497 & 9 & $P: 8, V: 3, G: 2$ \\
\hline
\end{tabular}

*GRAVY means Grand average of hydropathicity.

** Number of transmembrane helices predicted with TMHMM Server.

*** PSORT predictions: P (plasma membrane), V (vacuolar membrane), C (cytosol), Ch (chloroplast), N (nuclear), E.R. (endoplasmic reticulum), M (mitochondrion) and G (Golgi apparatus). 
Table 2 Oligopeptide transporter genes identified in Vitis

\begin{tabular}{|c|c|c|c|c|c|c|c|}
\hline Gene name & Gene ID & Genomic position & Protein Length & $\mathrm{pl}$ & GRAVY* & No. of $\mathrm{TMHs}^{*}$ & PSORT predictions* \\
\hline VVOPT1 & 100242147 & Chr18:6409616..6406367(-) & 757 & 6.51 & 0.46 & 14 & $P: 12, C: 1$ \\
\hline VVOPT2 & 100247286 & Chr18:6415993..6411758(-) & 754 & 8.61 & 0.377 & 16 & P: 12, V: 1 \\
\hline VvOPT3 & 100242155 & ChrUn:18477250..18484183(+) & 715 & 8.78 & 0.359 & 14 & $P: 10, C: 2, V: 1$ \\
\hline VVOPT4 & 100250922 & Chr3:10834213..10825455(-) & 744 & 8.59 & 0.438 & 14 & P: 13 \\
\hline VvOPT5 & 100267883 & ChrUn:18469581..18480735(+) & 533 & 9.25 & 0.371 & 9 & P: 10, E.R.: 3 \\
\hline VVOPT6 & 100249762 & Chr19:8962812..8965954(+) & 745 & 8.7 & 0.435 & 16 & P: 8, C: 3, E.R.: 2 \\
\hline VvOPT7 & 100257243 & Chr16:21603624..21599997(-) & 722 & 9.33 & 0.46 & 14 & P: 12, E.R.: 1 \\
\hline VVOPT8 & 100259035 & Chr18:6402500..6398183(-) & 759 & 8.91 & 0.43 & 15 & P: 7, V: 4, E.R.: 2 \\
\hline VvOPT9 & 100251260 & Chr2:2104857..2109137(+) & 752 & 5.61 & 0.434 & 14 & $P: 13$ \\
\hline VVOPT10 & 100256645 & Chr19:8994304..8997460(+) & 753 & 8.95 & 0.399 & 14 & P: 7, C: 4, E.R.: 2 \\
\hline VVYSL1 & 100242270 & Chr1:1967827..1970932(+) & 718 & 8.71 & 0.452 & 14 & P: 8, E.R:: 4, V: 2 \\
\hline VVYSL2 & 100249683 & Chr17:14986220..14981193(-) & 708 & 7.44 & 0.355 & 14 & P: 9, V: 2, G: 2 \\
\hline VVYSL3 & 100255514 & Chr16:21498741..21495037(-) & 655 & 8.99 & 0.508 & 14 & P: 10, V: 2, E.R:: 2 \\
\hline VVYSL4 & 100256406 & Chr17:14425936..14430684(+) & 704 & 8.77 & 0.347 & 14 & P: 10, G: 2, V: 1 \\
\hline VVYSL5 & 100252983 & Chr17:14475366..14480298(+) & 708 & 8.36 & 0.329 & 14 & P: 9, V: 2, G: 2 \\
\hline VVYSL6 & 100260063 & Chr14:25417683..25408791(-) & 649 & 5.74 & 0.588 & 12 & $V: 9, P: 4$ \\
\hline VVYSL7 & 100244078 & Chr1:1989810..1993774(+) & 713 & 8.95 & 0.347 & 14 & P: 8, E.R.: 4, V: 2 \\
\hline VVYSL8 & 100233121 & Chr2:2172478..2175411(+) & 661 & 9.04 & 0.498 & 14 & P: $10, V: 2$, E.R:: 2 \\
\hline
\end{tabular}

*Notes of GRAVY, TMH and PSORT are shown in Table 1.

(TMHs) (Tables 1 and 2). Further analyses using the protein subcellular localization prediction software WoFL PSORT http://wolfpsort.org enabled us to predict the probable protein localization for each of the different candidate OPTs in Vitis and Populus. It was found that all candidate OPTs identified in our study are most likely to be localized in the plasma or vacuolar membranes. PtOPT1, PtOPT4, VvOPT4 and VvOPT9 had a $100 \%$ probability of being localized to the plasma membrane. For all other OPTs, although the plasma membrane was predicted as the most likely location, it is also possible that they are localized to the membranes of organelles such as the chloroplast, nucleus or Golgi apparatus (Tables 1 and 2).

\section{Phylogenetic analyses, classification and functional relatedness of the OPT genes in Arabidopsis, rice, Populus and Vitis}

To examine the phylogenetic relationships among the OPT genes in Arabidopsis, rice, Populus and Vitis, we performed phylogenetic analyses of the OPT protein sequences from all four species based on a maximum likelihood method using PhyML 3.0 [29] and Bayesian analyses using PhyloBayes 3 [30]. Our results show that the OPT genes from the four higher plants consist of two major clades: the OPT and YSL classes. In this study, we further divide the YSL class into six subclasses according to their phylogenetic relationships and they are designated as Groups 1-6. The OPT class is also further divided into five subclasses, namely Groups 7-11 (Figure 1). The relationships of OsYSL1 with other OPT genes, however, cannot be confidently determined in our analyses: OsYSL1 was basal to a large clade consisting of Groups 2-6 with weak support in the maximum likelihood analyses, but formed a clade with Group 1 in Bayesian analyses. Therefore, OsYSL1 is not classified into any group in this study. Most of the designated groups are supported by decent bootstrap values and/or posterior probabilities. Moreover, other lines of evidence, such as gene structure and motif compositions as described below, also support the group classification in our analyses. Groups 4, 6 and 10 constitute the largest clades in the OPT phylogeny, each containing 11 members. Additionally, Groups 5 and 6 form a well supported clade in the maximum likelihood analyses, suggesting that they likely evolved from a common ancestor by frequent gene duplication.

Genes with same functions often are closely related and this has been confirmed in previous reports $[18,23,31,32]$. Such a trend is also found in the OPT genes. For instances, Group 4 includes the AtYSL1 and AtYSL3 proteins, both of which are involved in metal ion homeostasis and the loading of metal ions in seeds [33,34]. AtYSL1 and AtYSL3 proteins also have dual roles in reproduction: their activity in leaves is required for normal fertility and normal seed development, while their activity in inflorescences is required for proper loading of metals into seeds [35]. Another member in this group, OsYSL2, has metal-nicotianamine transport activities in heterologous expression systems [12]. AtOPT6, a member of Group 9, is able to transport glutathione derivatives and metal complexes under sulfur- 
deprived conditions and may be involved in stress resistance, whereas AtOPT7 of Group 8 is not involved in stress resistance $[19,21]$. The high AtOPT6 expression reported in the vasculature of roots, stems and leaves also suggests that this protein is involved in long-distance peptide transport or distribution throughout the plant $[19,20]$.

Phylogenetic analyses can allow us to identify evolutionarily conservative and divergent OPT genes. Remarkably, Groups 1 and 2 do not include any Arabidopsis, Vitis or Populus OPT proteins but contain only proteins from rice. Likewise, Group 9 does not include any rice OPT proteins but contains only proteins from Populus, Vitis and Arabidopsis. It is possible that these groups have evolved after monocot-dicot divergence and that they have specialized roles in monocots or dicots. Our phylogenetic analyses also show that Groups 4 and 5 contain sequences from rice, Vitis and Populus but not from Arabidopsis, indicating that they were either acquired in rice, Vitis and Populus or lost in Arabidopsis. Although enormous evidences indicates that all these OPT genes encode membrane proteins that translocate their substrates from either the extracellular environment or an organelle into the cytosol, their exact functional roles are different $[9-17,19,20]$. The phylogenetic analyses conducted in our study may also provide potential support for their functional differentiation. Additional evidence supporting this notion comes from the tissue-specific expression profiling available on GENEVESTIGATOR [36] and the extremely different expression pattern of OPTs in rice (see additional file 1: Microarray based expression profiles of rice OPT genes across a variety of tissue or organs). For example, OsYSL15 is specifically highly expressed in rhizomes, suggesting a specific role in root development. While OsYSL1, OsYSL3, OsYSL4, OsYSL7, OsYSL8 and OsYSL11 show higher expression levels in pollen, indicating a key role in pollen development or reproduction.

Our phylogenetic analyses also show that several pairs of OPT proteins are putative paralogs (Figure 1). These putative paralogous OPT proteins account for over $44.4 \%, 40 \%, 33.3 \%$ and $40 \%$ of the entire OPT family in Vitis, Populus, Arabidopsis and rice, respectively, with sequence identifies ranging from $61 \%$ to $98 \%$ (see additional file 2: Pairwise identities between homologous pairs of OPT genes from Vitis, Populus, Arabidopsis and rice). These paralogous OPT members are closely related within the species, and have a very similar structure as described below (middle panel in Figure 1), indicating that they evolved from relatively recent gene duplications. We also estimated the evolutionary dates of the segmental duplication events using $K_{s}$ as the proxy for time (Table 3). Three of the four pairs (PtOPT1/ PtOPT5, PtYSL1/PtYSL2, PtYSL8/PtYSL9) in Populus
Table 3 Inference of duplication time in paralogous pairs

\begin{tabular}{cccc}
\hline Paralogous pairs & $\boldsymbol{K}_{\boldsymbol{a}}$ & $\boldsymbol{K}_{\boldsymbol{s}}$ & Data (million years ago) \\
\hline VvOPT1/NVOPT2 & 0.1004 & 0.47699 & 36.69 \\
VvOPT3/NVOPT5 & 0.03518 & 0.07756 & 5.97 \\
VvOPT10/NVOPT6 & 0.0241 & 0.02577 & 1.98 \\
VVYSL2NVYSL4 & 0.01133 & 0.02049 & 1.58 \\
PtOPT1/PtOPT5 & 0.03736 & 0.24447 & 13.43 \\
PtOPT6/PtOPT7 & 0.01565 & 0.03607 & 1.98 \\
PtYSL1/PtYSL2 & 0.12045 & 0.3011 & 16.54 \\
PtYSL8/PtYSL9 & 0.05279 & 0.28604 & 15.71 \\
AtOPT6/AtOPT9 & 0.10962 & 0.99913 & 33.3 \\
AtOPT1/AtOPT5 & 0.12939 & 0.80831 & 26.94 \\
OsOPT1/OsOPT8 & 0.13652 & 0.67946 & 52.27 \\
OsOPT2/OsOPT3 & 0.0631 & 0.3515 & 27.04 \\
OsYSL3/OsYSL4 & 0.17389 & 0.48266 & 37.13 \\
OsYSL7/OsYSL17 & 0.29914 & 0.80453 & 61.89 \\
OsYSL11/OsYSL12 & 0.1657 & 1.03669 & 79.75 \\
\hline
\end{tabular}

have very consistent $K_{s}$ values (from 0.24447 to 0.30110 ), suggesting that the duplication events in this species occurred within the last 13.43 to 16.54 million years. This period is consistent with the time (13 Ma) when a recent large-scale genome duplication event is thought to have occurred in Populus [37]. For rice, the segmental duplication event was estimated to have occurred between 27.04 to $106.11 \mathrm{Ma}$, following the divergence of monocots and eudicots (170-235 Ma). Among them, about half of the rice OPT duplication events occurred approximately when grasses originated (55-70 Ma) [38-40]. It is interesting that four of the OPT gene duplications (PtOPT6/PtOPT7, VvOPT3/ VvOPT5, VvOPT10/VvOPT6, VvYSL2/VvYSL4) were estimated to have occurred more recently (only about 1.58 to $5.97 \mathrm{Ma}$ ). These relatively recent duplications were not found in Arabidopsis or rice. It is likely that Arabidopsis and rice have subsequently suffered a high level of gene loss [41].

\section{Exon-intron evolution of the OPT family genes in Arabidopsis, rice, Populus and Vitis}

To investigate the mechanisms of the structural evolution of OPT paralogs, we compared the exon-intron structure of individual OPT genes in Arabidopsis, rice, Populus and Vitis. Figure 1 provides a detailed illustration of the distribution and position of introns within each of the OPT paralogs. In general, the positions of some spliceosomal introns are conserved in orthologous genes from the four lineages. In many cases, not only is the intron position shared, but the intron phase is shared as well. Moreover, the conservation of the exonintron organization or gene structure in paralogous genes is usually strong and sufficient to reveal evolutionary relationships of introns [42]. It is clear that 
duplication plays an important role in the organization of genes and that intron losses have occurred frequently after segmental duplication [43]. Our study of AtOPT6/ AtOPT9 and OsOPT1/OsOPT8 duplication also suggests that this mechanism underlies the evolution of these paralogs and intron losses are associated with duplications (Figure 1). The phenomenon of intron loss following gene duplication also occurred in the evolution of many other genes including the aromatic amino acid hydroxylase (AAAH) family [44]. In general, the structural diversity of gene family members provides a mechanism for the evolution of multiple gene families, while intron loss or gain can be an important step in generating structural diversity and complexity $[45,46]$. In this study, we analyzed the structural diversity of OPT genes and found that intron loss/gain events occurred during the expansion and structural evolution of OPT paralogs. We found that most OPT genes in the same subgroups/clades have similar coding sequences and a very similar exon-intron structure, strongly supporting their close evolutionary relationship. The divergent gene structures in the different phylogenetic subgroups may represent gene family expansion from ancient paralogs or multiple origins of gene ancestry.

\section{Chromosomal location of the OPT genes and duplication events in the genome}

Genome-wide duplication events, gene loss and local rearrangements have created the present complexities of the genome. To further investigate the relationship between the genetic divergence within the OPT family and gene duplication and loss in the Populus and Vitis genomes, we determined the chromosomal location of each OPT gene. The results show that the OPT genes are dispersed throughout the Populus and Vitis genomes. Three of the Populus OPT genes are localized to unassembled genomic sequence scaffolds and thus could not be mapped to any particular chromosome. The other OPT genes are distributed unevenly among the eight chromosomes of the Populus genome (Figure 2).

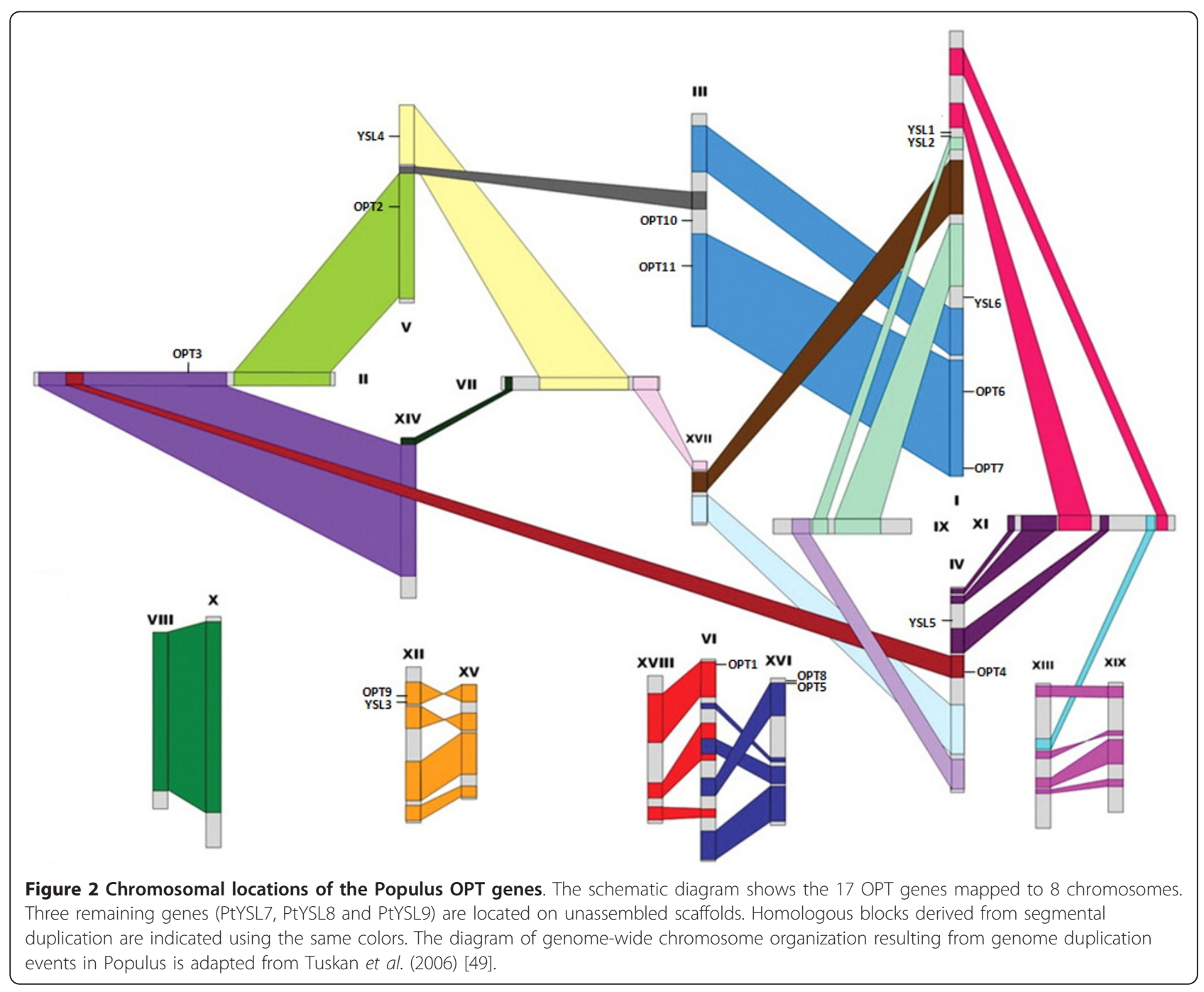


Five OPT genes were identified on chromosome I, two on each of chromosomes III, IV, V and XII, and only one on each of chromosomes VI and II. For Vitis, 16 OPT genes were found on 8 of the 19 chromosomes; three on each of chromosomes XVII and XVIII, two on each of chromosomes I, II, XVI and XIX, and one on each of chromosomes III and XIV (Figure 3). Two other Vitis OPT genes could not to be assigned to a specific chromosome.

Gene duplication events are thought to have frequently occurred in organismal evolution $[47,48]$. To investigate the relationship between the OPT genes and potential gene duplications within the genome, we also compared the locations of OPT genes in duplicated chromosomal blocks that were previously identified in Populus, Vitis, Arabidopsis and rice [41,49-52]. The distribution of the OPT genes relative to the corresponding duplicated chromosomal blocks is illustrated in Populus (Figure 2), Vitis (Figure 3), Arabidopsis (see additional file 3: Chromosomal locations of the Arabidopsis OPT genes) and rice (see additional file 4: Chromosomal locations of the rice OPT genes). This result suggests that segmental duplication and transposition events are not the major factors that led to the expansion of the OPT gene family in the four higher plants. It may be that dynamic changes occurred following segmental duplication, leading to loss of many of the genes. Interestingly, we found that some OPT genes are located in tandem clusters on the chromosomes; examples are PtYSL1-PtYSL2, PtOPT8-PtOPT5, AtOPT9-AtOPT8, OsYSL7-OSYSL8, OsYSL2-OsYSL15, OsYSL9-OsYSL16,
OsYSL3-OsYSL4, OsOPT2-OsOPT3 and VvOPT1VvOPT2-VvOPT8 (Figure 2 and 3; see also additional file 3: Chromosomal locations of the Arabidopsis OPT genes and additional file 4: Chromosomal locations of the rice OPT genes). Further analyses indicate that most of the tandemly clustered OPT pairs share relatively high similarities (mostly above $70 \%$ ). Thus, we propose that tandem duplications might have been an important factor governing the expansion of the OPT gene family in these species.

\section{Conserved domains and motifs in OPT proteins}

The major domains of the OPT proteins in Populus, Vitis, Arabidopsis and rice were identified using CDD, Pfam and SMART $[27,28]$. Our results show that all OPT proteins in the four species possess only one characteristic and structurally conserved OPT domain essential for their transporter activity. While these tools are suitable for defining the presence or absence of recognizable domains, they are unable to recognize smaller individual motifs and more divergent patterns. Thus, we further used the program MEME [53] to study the diversification of OPT genes in Populus, Vitis, Arabidopsis and rice. Twenty distinct motifs were identified in these genes (Figure 1). Details of the 20 motifs are presented in additional file 5: Sequence logo and regular expression of the different motifs identified in the OPT gene family. As mentioned above, phylogenetic analyses broadly divided the OPT genes from the four higher plants into two major classes, the OPT class and the YSL class. Noticeably, most of the closely related

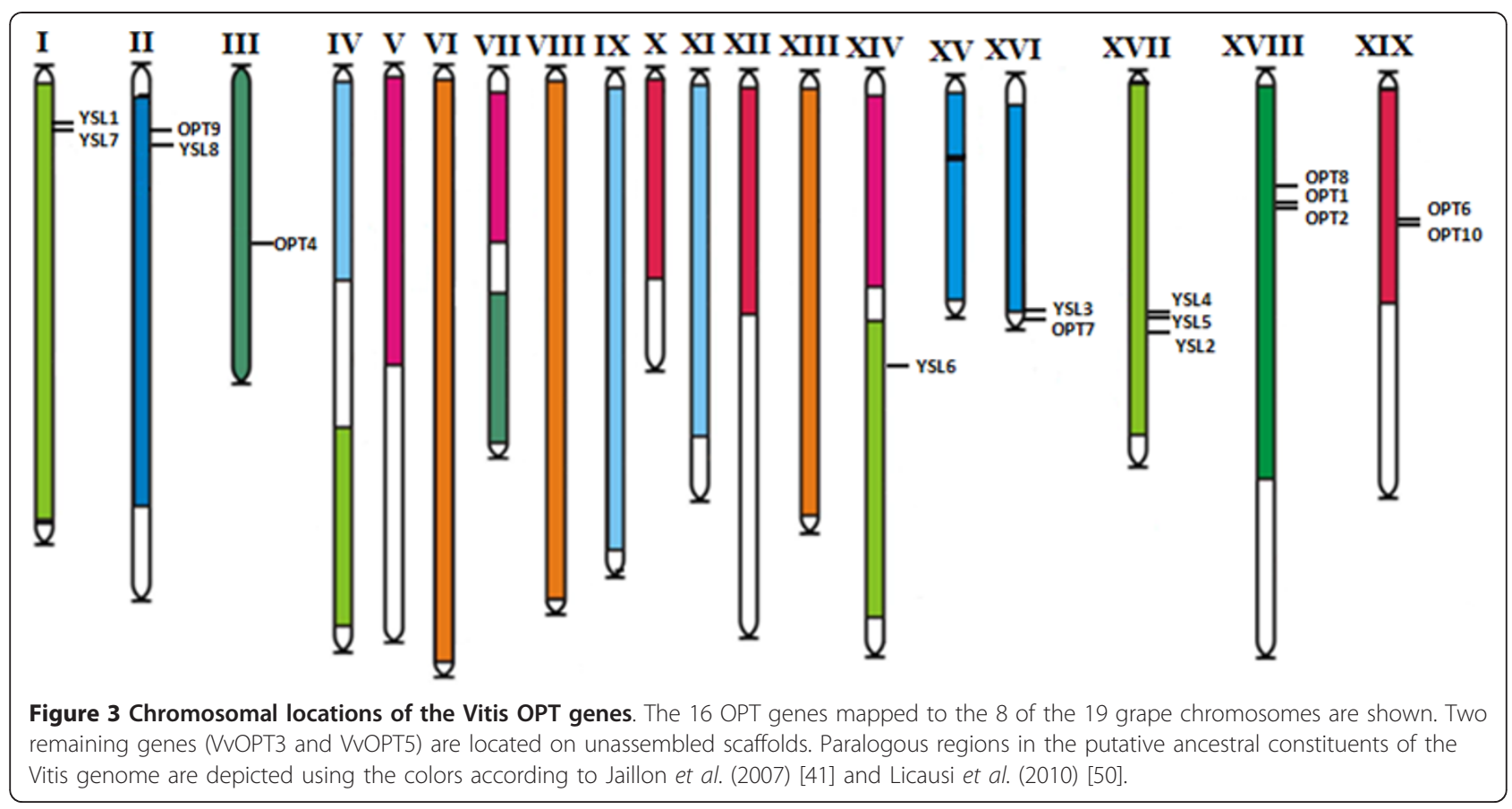


members in each of these two main classes have common motif compositions, suggesting functional similarities among the OPT proteins within the same class (Figure 1). Most members of OPT class possess 14 motifs, while most members of YSL class have 9 motifs. Three of the motifs (motif 1 , motif 2 and motif 7 ) are shared by all OPT proteins. Whether the motifs that are specific to the OPT class (motif 3, 4, 5, 9, 10, 12, 15, 16, 17,18 and 19) or to the YSL class (motif 6, 8, 11, 13, 14 and 20) confer unique functional roles to the OPTs remains to be further investigated. In any case, the conserved motifs in the OPT proteins from the same class may provide additional support to results of the phylogenetic analyses. On the other hand, the divergence in motif composition among different classes may indicate that they are functionally diversified.
Differential expression profiles of the Populus and Vitis OPT genes

Expression profiling can provide useful clues to gene functions. To examine the expression patterns of the OPT genes, we performed a comprehensive expression analysis using some of the publicly available microarray data for Populus and Vitis. In general, the expression levels of most OPT genes in Populus peaked in shoot apices, roots and internode 9 (Figure 4). Because these are the growing points of plants, they are likely to need more nutrients to ensure plant growth and differentiation. Because OPTs are membrane-localized proteins and have a broad range of substrate transport capabilities, higher expression of OPTs in these parts might contribute to many growth and developmental processes. Some OPTs seem not to follow this trend. For
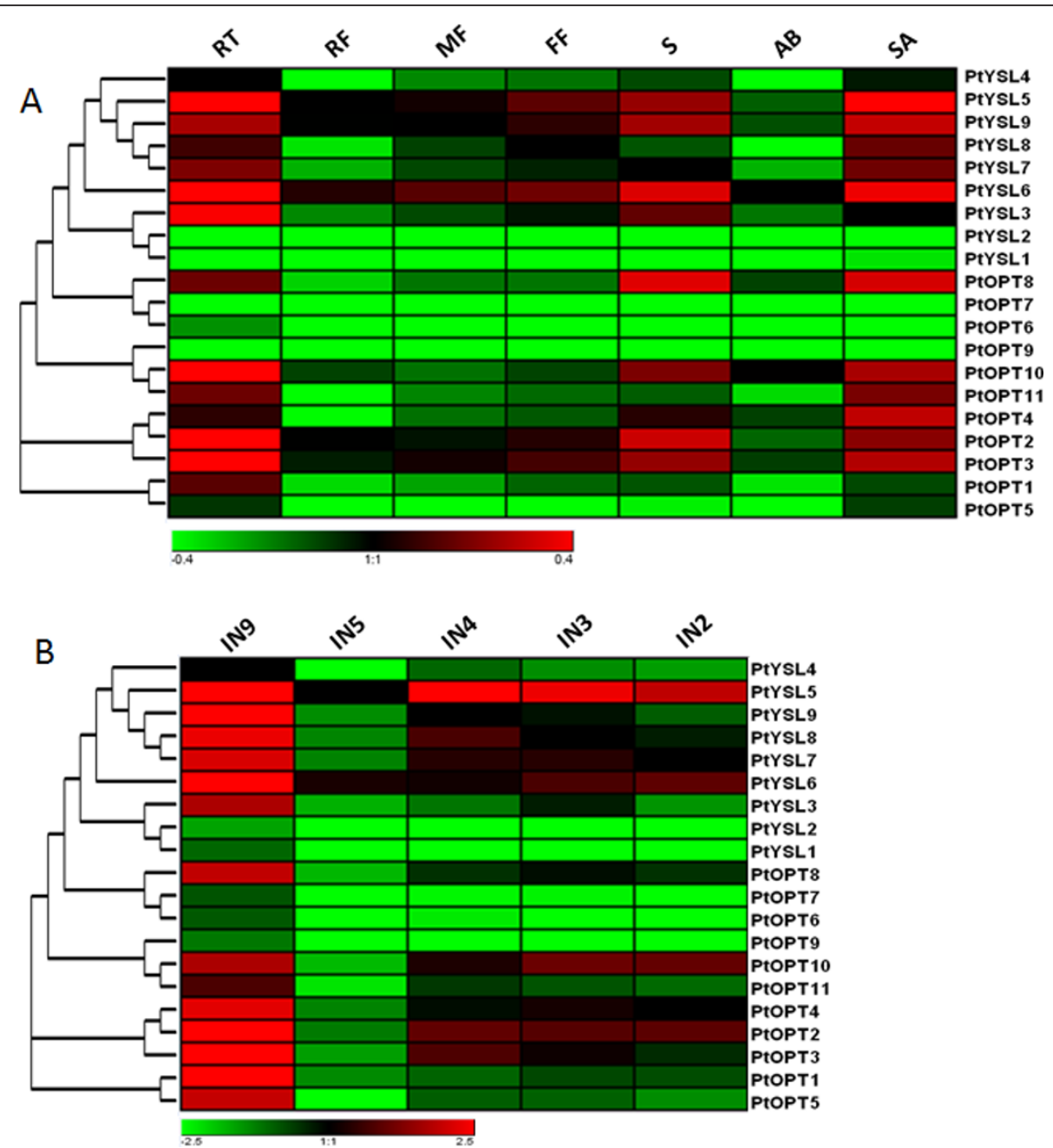

Figure 4 Expression profiles of the Populus OPT genes. A. Dynamic expression profiles from GEO: GSE21481 of the 20 OPT genes in different tissues. RT, roots from tissue culture; RF, roots from field trees; MF, male floral bud initials; FF, female floral bud initials; S, seedling 43 hr postimbibition; AB, axillary buds; SA, shoot apex. B. Expression profiles from GEO: GSE13043 of the 20 OPTs in different internodes. IN9, internode 9; IN5, internode 5; IN4, internode 4; IN3, internode 3; IN2, internode 2. 
example, PtOPT10 displayed especially high expression levels in internode 2 .

Grape and wine production is strongly affected by environmental cues during the development of the plant. Here, we also investigated the expression pattern of the OPT genes in response to some abiotic stresses. Because sunshine duration can affect the quality of fruits, long daylight hours will cause grape plants to produce more carbohydrates (e.g. sucrose). Microarray data indicate that some OPTs vary considerably in their expression levels when exposed to long daylight (LD) or short daylight (SD) (Figure 5A). VvOPT2, VvYSL3 and VvYSL7 showed higher expression levels in LD compared with in SD. One possible explanation may be that, in LD conditions, grape plants need more transporters (such as the OPTs) to transport more oligonucleotide peptides for increased carbohydrate synthesis. We also examined the expression patterns of the Vitis OPTs under different stress conditions. Interestingly, several genes such as VvYSL1 and VvYSL2 showed low expression levels when treated with ABA, whereas a subset of genes including VvYSL3, VvOPT6 and VvOPT10 displayed high expression levels under salt stress (Figure $5 \mathrm{C})$. Similarly, several genes such as VvOPT3 and
VvYSL7 demonstrated depressed expression patterns in cold conditions. We further selected four growth phases of the fruit to investigate the different expression of the OPT genes in the fruit maturing process. These four phases were green hard berry, green soft berry, pink soft berry and red soft berry. As shown in Figure 5B, different expression levels of the OPTs genes were found in the four different growth phases of the fruit, suggesting divergent functions of the OPT members in the maturing process.

Duplicated genes may have different evolutionary fates [54], which can be indicated by divergence in their expression patterns. Because tandem duplications may have governed the expansion of the OPT gene family, we also investigated the expression profiles of the duplicated OPT gene pairs identified above in Populus and Vitis. Our results show that none of the gene pairs share similar expression patterns (Figure 4 and 5), indicating that substantial neofunctionalization may have occurred during the subsequent evolution of the duplicated genes. It seems that the expression patterns of the paralogs have diverged during long-term evolution, suggesting functional diversification of the duplicated genes [55-58]. Such a process may increase the adaptability of

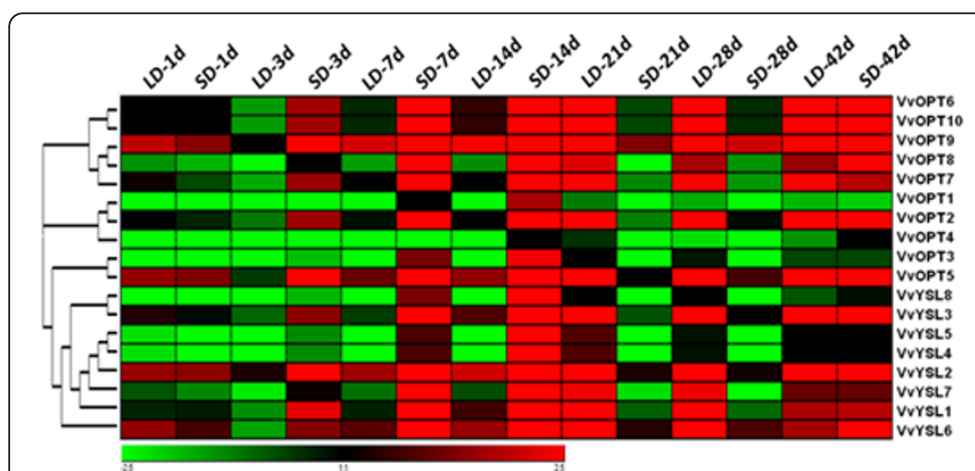

A

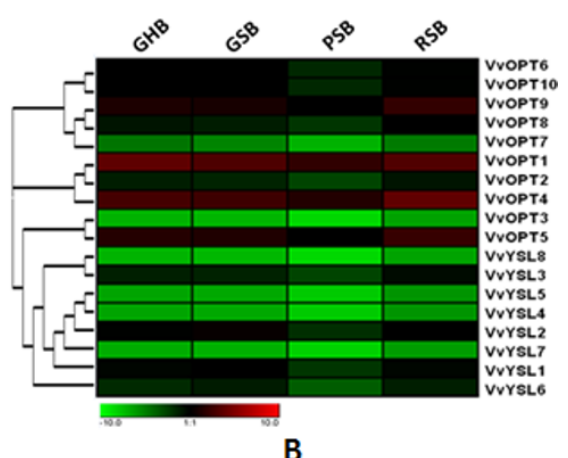

B
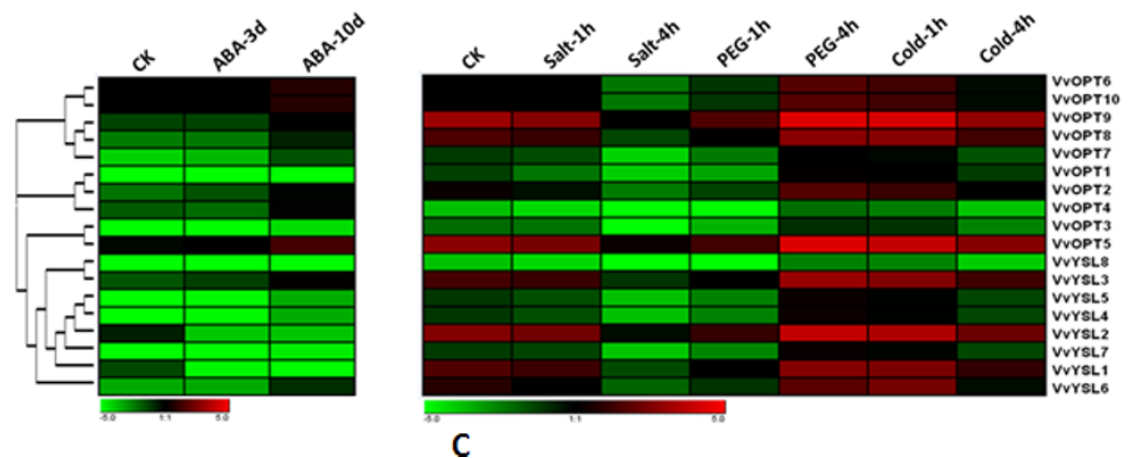

Figure 5 Expression profiles of the Vitis OPT genes. A. Expression patterns from GEO: GSE17502 of the 18 OPTs for different sunshine durations. LD-1d, long day (15 h) for 1 day; SD-1d, short day (13 h) for 1 day and so forth. B. Hierarchical clustering of the expression profiles from GEO: GSE11406 of the 18 OPT genes for different fruit development periods. GHB, green hard berry; GSB, green soft berry; PSB, pink soft berry; RSB, red soft berry. C. Expression profiles from PLEXdb: W1-RMA and W17-RMA of the 18 OPTs under different stress conditions. 
duplicated genes to environmental changes, thus conferring a possible evolutionary advantage.

\section{Analysis of functional divergence}

Next, we investigated whether amino acid substitutions in the highly conserved OPT domain could have caused adaptive functional diversification. Type-I functional divergence between gene clusters of the OPT family was estimated by posterior analysis using the program DIVERGE $[59,60]$, which evaluate the shifted evolutionary rate and altered amino acid properties. Comparisons of thirty-five pairs of paralogous members and class $\mathrm{OPT} /$ class YSL proteins were carried out and the rate of amino acid evolution at each sequence position was estimated. Our results indicate that the coefficient of all functional divergence $(\theta)$ values between these groups or classes is less than 1 (Table 4). These observations indicate that there were significantly site-specific altered selective constraints on most members of the OPT family, leading to group-specific functional evolution after diversification. Moreover, critical amino acid residues responsible for the functional divergence were predicted based on site-specific profiles in combination with suitable cut-off values derived from the posterior probability of each comparison. The results indicate distinct differences in the number and distribution of predicted sites for functional divergence within each pair. For example, no critical amino acid site was predicted for the sequences in the Group 2/5, 4/5 and 9/11 pairs (Figure 1), while over 200 critical amino acids sites were predicted for Group 2/7, 2/8, 2/9, 2/10, 2/11, 4/7, 4/8, $4 / 9,4 / 10,4 / 11,5 / 7,5 / 8,5 / 9,5 / 10,5 / 11,6 / 7,6 / 8,6 / 9$ and $6 / 10$ pairs. Interestingly, when the OPT sequences in the OPT and YSL classes were compared, thirty-one critical amino acid sites were predicted for Group 6/11 pairs. When a cut-off value of 0.7 was applied, only four substitution sites were predicted, implying a lower evolutionary rate between the two pairs.

During a long period of evolution, the different evolutionary rates at specific amino acid sites within each pair might promote the functional divergence of OPT subfamilies. In Table 4 , we also find that higher theta values $(\theta)$ exist in Group 2/8 (0.9992) and Group 2/10 (0.9992), indicating a higher evolutionary rate or sitespecific selective relaxation between them. An example of the residues predicted to be functionally divergent was mapped onto the topology models of the Group 7/9 members (Figure 6). The predicted functional sites are not equally distributed throughout the OPT sequence, but are distributed in different $\alpha$-helices and $\beta$-strands. The functions of these sites need to be experimentally verified. Thus, the results of the functional divergence analysis suggest that, because of the different evolutionary rates predicted at some amino acid sites, the OPT
Table 4 Functional divergence estimated in OPT paralogs

\begin{tabular}{|c|c|c|c|c|c|}
\hline Comparison & $\theta^{1}$ & $\mathrm{SE}^{2}$ & $\mathrm{LRT}^{3}$ & $\mathrm{~N}(0.5)^{4}$ & $\mathrm{~N}(0.7)^{4}$ \\
\hline Class YSL/Class OPT & 0.8592 & 0.035797 & 576.1111 & 277 & 259 \\
\hline Group 2/Group 5 & 0.001 & 0.022361 & 0 & 0 & 0 \\
\hline Group 2/Group 6 & 0.4576 & 0.085419 & 28.69854 & 68 & 24 \\
\hline Group 2/Group 7 & 0.8136 & 0.111007 & 53.71832 & 280 & 272 \\
\hline Group 2/Group 8 & 0.9992 & 0.110362 & 81.9717 & 280 & 280 \\
\hline Group 2/Group 9 & 0.78 & 0.149011 & 27.40026 & 280 & 261 \\
\hline Group 2/Group 10 & 0.9992 & 0.085793 & 135.6435 & 280 & 280 \\
\hline Group 2/Group 11 & 0.8176 & 0.183891 & 19.76782 & 280 & 277 \\
\hline Group 4/Group 5 & 0.0682 & 0.096501 & 0.499466 & 0 & 0 \\
\hline Group 4/Group 6 & 0.2944 & 0.067278 & 19.14823 & 31 & 7 \\
\hline Group 4/Group 7 & 0.6616 & 0.07072 & 87.5186 & 262 & 187 \\
\hline Group 4/Group 8 & 0.8456 & 0.081838 & 106.7636 & 279 & 272 \\
\hline Group 4/Group 9 & 0.664 & 0.084659 & 61.51604 & 256 & 211 \\
\hline Group 4/Group 10 & 0.8112 & 0.063991 & 160.7009 & 278 & 255 \\
\hline Group 4/Group 11 & 0.6936 & 0.093695 & 54.80009 & 271 & 233 \\
\hline Group 5/Group 6 & 0.0162 & 0.106826 & 0.022997 & 3 & 2 \\
\hline Group 5/Group 7 & 0.6824 & 0.104652 & 42.5189 & 270 & 212 \\
\hline Group 5/Group 8 & 0.808 & 0.11001 & 53.9456 & 277 & 272 \\
\hline Group 5/Group 9 & 0.6632 & 0.138302 & 22.99485 & 272 & 220 \\
\hline Group 5/Group 10 & 0.8264 & 0.088168 & 87.85369 & 279 & 268 \\
\hline Group 5/Group 11 & 0.5936 & 0.149554 & 15.75407 & 263 & 239 \\
\hline Group 6/Group 7 & 0.7312 & 0.068942 & 112.4879 & 272 & 215 \\
\hline Group 6/Group 8 & 0.7312 & 0.076661 & 90.97606 & 271 & 222 \\
\hline Group 6/Group 9 & 0.58 & 0.075415 & 59.1481 & 233 & 157 \\
\hline Group 6/Group 10 & 0.7152 & 0.05871 & 148.3988 & 266 & 212 \\
\hline Group 6/Group 11 & 0.3656 & 0.089522 & 16.67828 & 31 & 4 \\
\hline Group 7/Group 8 & 0.1832 & 0.063668 & 8.279587 & 9 & 2 \\
\hline Group 7/Group 9 & 0.3552 & 0.07426 & 22.87913 & 30 & 11 \\
\hline Group 7/Group 10 & 0.2584 & 0.055745 & 21.4871 & 27 & 7 \\
\hline Group 7/Group 11 & 0.1264 & 0.071182 & 3.153215 & 2 & 1 \\
\hline Group 8/Group 9 & 0.1 & 0.06825 & 2.146829 & 1 & 0 \\
\hline Group 8/Group 10 & 0.168 & 0.060741 & 7.649795 & 4 & 2 \\
\hline Group 8/Group 11 & 0.2936 & 0.100349 & 8.560273 & 10 & 2 \\
\hline Group 9/Group 10 & 0.148 & 0.068012 & 4.73535 & 3 & 0 \\
\hline Group 9/Group 11 & 0.1058 & 0.1249 & 0.71754 & 0 & 0 \\
\hline Group 10/Group 11 & 0.156 & 0.088912 & 3.078442 & 2 & 0 \\
\hline
\end{tabular}

${ }^{1} \theta$ is the coefficient of functional divergence.

${ }^{2} \mathrm{SE}$ : standard error.

${ }^{3}$ LRT is a likelihood ratio test.

${ }^{4} \mathrm{~N}(0.5)$ and $\mathrm{N}(0.7)$ means the numbers of divergent residues when the cut-off value is 0.5 and 0.7 , respectively.

genes may be significantly divergent from each other in their functions. Perhaps, amino acid mutations have spurred the OPT family genes to evolve new functions after divergence and hence, functional divergence might reflect the existence of long-term selective pressures.

\section{Variable selective pressures among amino acid sites}

The $K_{a} / K_{s}$ ratio measures selection pressure on amino acid substitutions. A $K_{a} / K_{s}$ ratio greater than 1 suggests positive selection and a ratio less than 1 suggests 


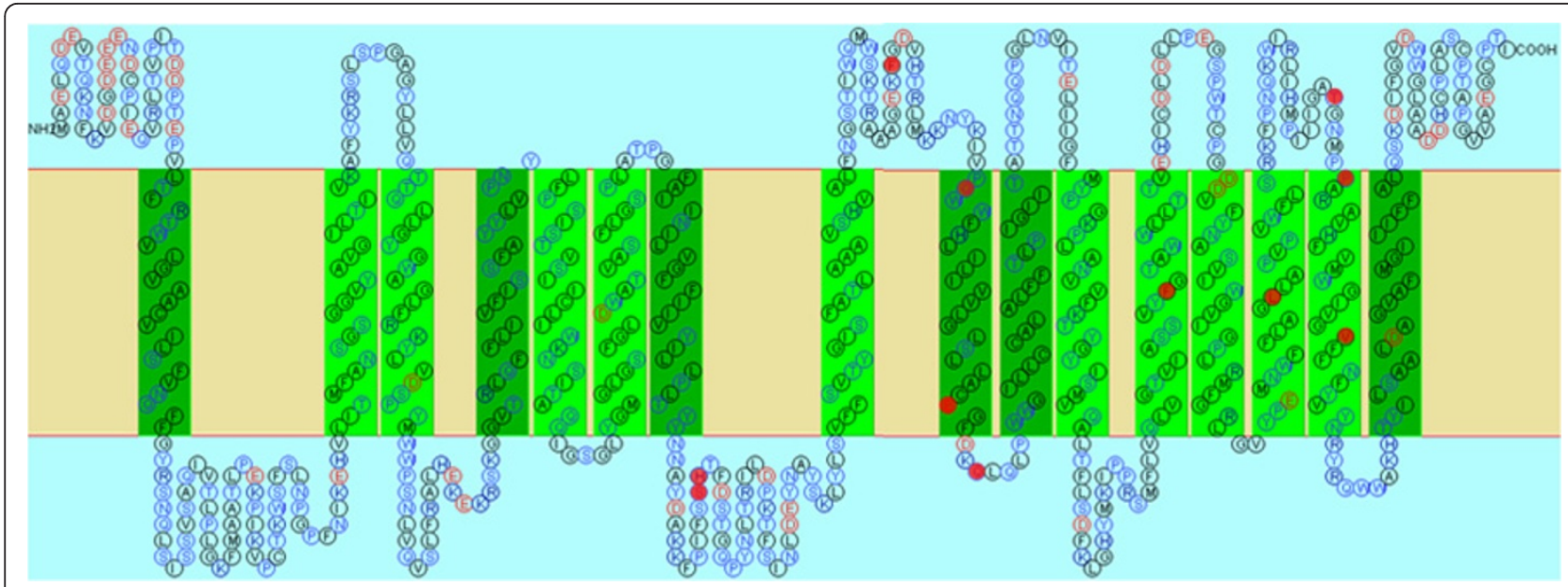

Figure $\mathbf{6}$ Site specific profiles for evolutionary rate changes in Groups $\mathbf{7}$ and 9. Eleven critical amino acid residues likely responsible for the functional divergence of these two groups were predicted and are shown in the filled red circles on the membrane topology model of VvOPT6, which was based on site-specific profiles combined with a suitable cut-off values (0.7) derived from the posterior probability of Group 7 and Group 9 comparison. Predicted membrane-spanning structure of VvOPT6 was generated by the computer topology prediction program SOSUI [77].

purifying selection. The amino acids in a protein sequence are expected to be under different selective pressures and to have different underlying $K_{a} / K_{s}$ ratios. To analyze positive or negative selection of specific amino acid sites within the full-length sequences of the OPT proteins in the different OPT groups, substitution rate ratios of nonsynonymous $\left(K_{a}\right)$ versus synonymous $\left(K_{s}\right)$ mutations were calculated with the Selecton Server http://selecton.tau.ac.il using a Bayesian inference approach [61]. The results show that the $K_{a} / K_{s}$ ratios of the sequences from the different OPT groups are significantly different (Figure 7A). However, despite the differences in $K_{a} / K_{s}$ values, all the estimated $K_{a} / K_{s}$ values are substantially lower than 1 , suggesting that the OPT sequences within each of the Groups are under strong purifying selection pressure and that positive selection may have acted only on a few sites during the evolutionary process. We performed the tests using the M8 $\left(\omega_{\mathrm{s}}>\right.$ = 1), and M7 (beta) models. The selection model M7 does not indicate the presence of positively selected sites, whereas the M8 model does (Figure 7A and 7B). It is thus clear that, while most of the protein sequence is subjected to constant purifying selection, a few sites undergo positive selection. The detailed distribution of the positive-selection sites in Group 4 sequences as predicted by the M8 model are showed in Figure $7 \mathrm{C}$. Further analyses indicate that six of the 10 positive selection sites in the Group 4 sequences are in $\alpha$-helices $(\alpha 1, \alpha 5$ and $\alpha 10)$. Interestingly, more than half of all the predicted positive-selection sites (Figure $7 \mathrm{~B}$ ) are in the $\beta 5 \beta$-strand ( 2 sites) and in the $\alpha 5$ helix ( 4 sites). These observations suggest that positive selection pressure on the $\beta$-strands $(\beta 2,4$ and $\beta 5)$ and $\alpha$-helices $(\alpha 1, \alpha 5$ and $\alpha 10)$ might have accelerated functional divergence and the formation of the multiple subgroups. A few additional positively selected sites are distributed in other $\alpha$ helices ( $\alpha 2-4$ and $\alpha 6-9$ ), suggesting that these residues might be important in maintaining the conformational stability of the proteins.

\section{Conclusion}

This study provides a comparative genome analysis addressing phylogeny, chromosomal location, gene structure, expression profiling, functional divergence and selective pressures of the OPT gene family in Populus and Vitis. Phylogenetic analyses revealed two wellsupported classes in the OPT family, each of which can be further classified into 5 to 6 distinct groups. The exon/intron structure and motif compositions of the OPT genes and proteins are highly conserved in each class and in each of the groups, indicative of their functional conservation. The OPTs genes are non-randomly distributed across the Populus and Vitis chromosomes, and a high proportion of the OPT genes may be derived from tandem duplications. An additional comprehensive analysis of the expression profiles has provided insights into the possible functional divergence among members of the OPT gene family. Furthermore, functional divergence analyses suggest that significant site-specific selective constraints may have acted on most OPT paralogs after gene duplication, leading to subgroup-specific functional evolution. These data may provide valuable information for future functional investigations of this gene family. 


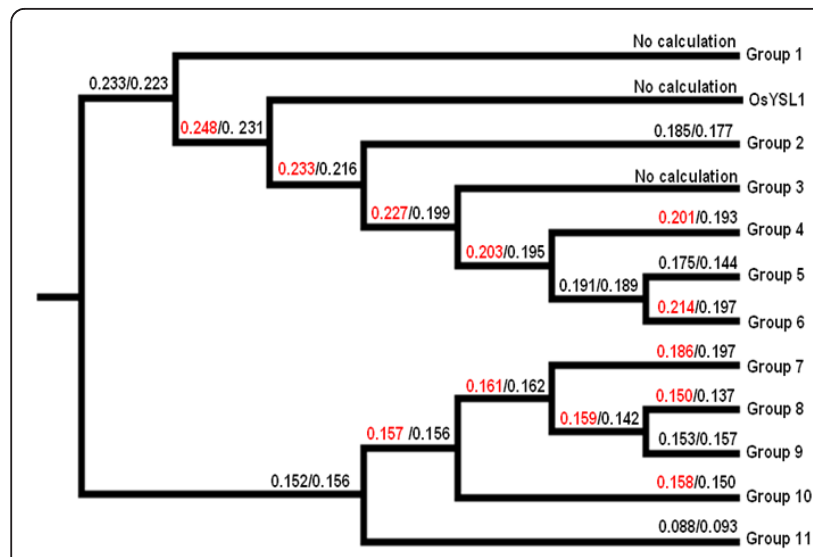

A

\begin{tabular}{|l|c|l|}
\hline Gene branchs & Log-likelihood & Positive selection sites \\
\hline Group 4 & -16098 & $30,99,305,362,365,366,367,369,373,588$ \\
\hline Group 6 & -13811.4 & $1,82,239,240,304,340,348,532$ \\
\hline Group 4-5-6 & -34895.9 & 8, \\
\hline Group 3-4-5-6 & -38702.7 & $\begin{array}{l}1,2,3,4,5,6,7,8,9,10,11,12,15,17,19,20,21, \\
22,29,30,31,37,348,360,363,364,368,588\end{array}$ \\
\hline Group 2-3-4-5-6 & -45683.2 & $4,11,15,135,232,297,329,349,359,575$ \\
\hline Group & -47686 & $2,3,4,6,7,14,16,18,234,298,330,344,345$, \\
2-3-4-5-6-OsYSL1 & & $347,362,363,592$ \\
\hline Group 7 & -13624.7 & 716, \\
\hline Group 8 & -13411.3 & $4,5,9,10,13,14,252$ \\
\hline Group 8-9 & -19623.5 & $5,7,9,10,11,212,433,634$ \\
\hline Group 7-8-9 & -32181.3 & 189,623, \\
\hline Group 7-8-9-10 & -47708.6 & 3,189, \\
\hline Group 10 & -17357.3 & $7,19,147,330,670$ \\
\hline
\end{tabular}

B

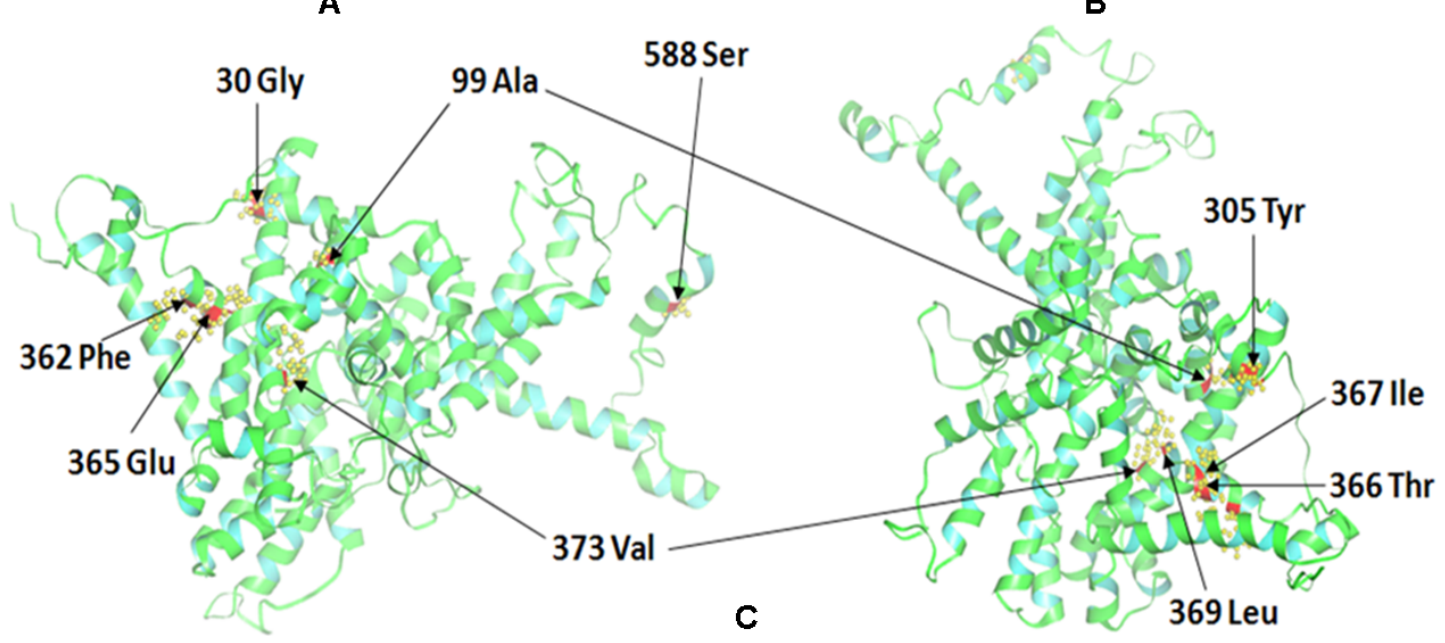

Figure 7 Positive selection assessment of the OPT gene family in Arabidopsis, Populus, Vitis and rice. A. Selection pressure $\left(K_{d} / K_{s}\right)$ of the full-length OPT protein sequences for the different phylogenetic groups. Two different evolution models (M8/M7) were used. The M8 model was the only one that predicted the presence of positively selected sites (shown in red). B. Likelihood values and parameter estimates for the OPT genes predicted to undergo positive selection pressure as described in A. C. Detailed distribution of the positive selection sites of Group 4 predicted by the M8 model. Ten potential positive-selection sites are marked with arrows and shown in red in the tertiary structure of the PtYSL2 protein.

\section{Methods}

\section{Sequence retrieval and identification}

To identify potential members of the OPT gene family in Populus and Vitis, we performed multiple database searches. Published Arabidopsis and rice OPT gene sequences $[18,23]$ were retrieved and used as queries in BLAST searches against the Poplar Genome database http://genome.jgj-psf.org and the Genoscope Grape Genome database http://www.cns.fr. BLAST searches were also performed against the Poplar and Grape genomes at National Center for Biotechnology Information (NCBI, http://www.ncbi.nlm.nih.gov) and Phytozome http://www.phytozome.net.

WoLF PSORT http://wolfpsort.org[62] was used to predict protein subcellular localization. The TMHMM server http://www.cbs.dtu.dk/services/TMHMM/ was used to estimate the number of transmembrane helical domains. The isoelectric point (pI), molecular weight and grand average hydropathy (GRAVY) values were estimated using the ProtParam tool from ExPASy http:// us.expasy.org/tools/protparam.html.

\section{Phylogenetic analyses of the OPT gene family}

Multiple sequence alignments of the full-length protein sequences were performed using MUSCLE 3.52 [63], followed by manual comparisons and refinement. Gaps and ambiguously aligned regions were removed before phylogenetic analyses. ModelGenerator [64] was used to determine the substitution model and rate heterogeneity that best fit the OPT protein data. Phylogenetic analyses were performed with a maximum likelihood method using PhyML 3.0 [29] and a Bayesian inference method using PhyloBayes 3 [30]. The LG model of protein sequence substitution [65] and four gamma rate 
categories, as determined by ModelGenerator, were used for both maximum likelihood and Bayesian analyses. Bootstrap analyses for maximum likelihood analyses were performed using 100 pseudoreplicates. For Bayesian analyses, two independent runs were carried out with default settings until a maxdiff value $=0.27$ was achieved to ensure chain equilibration $(4,300$ generations). The first 100 points were discarded as burn-in, and the posterior consensus was computed on the remaining trees. The topology depicted in Figure 1 was generated using PhyML.

\section{Inference of duplication time}

Pairwise alignment of nucleotide sequences of the OPT paralogs was performed using MEGA 5 [66]. Alignments were performed using ClustalW (codons). The $K_{a}$ and $K_{s}$ values of the paralogous genes were estimated by the program K-Estimator 6.0 [67]. To better explain the patterns of macroevolution, estimates of the evolutionary rates were considered extremely useful. Assuming a molecular clock, the synonymous substitution rates $\left(K_{s}\right)$ of the paralogous genes would be expected to be similar over time. Thus, $K_{s}$ could be used as the proxy for time to estimate the dates of the segmental duplication events. The $K_{s}$ value was calculated for each of the gene pairs and then used to calculate the approximate date of the duplication event $\left(\mathrm{T}=K_{s} / 2 \lambda\right)$, assuming clock-like rates $(\lambda)$ of synonymous substitution of $1.5 \times 10^{-8}$ substitutions/synonymous site/year for Arabidopsis [48], 6.5 $\times 10^{-9}$ for rice [68], $9.1 \times 10^{-9}$ for Populus [69], and 6.5 $\times 10^{-9}$ for Vitis [70].

\section{Chromosomal location and gene structure of the OPT genes}

The chromosomal locations of the OPT genes were determined using the Populus genome browser http:// www.phytozome.net/poplar and Vitis genome browser http://www.genoscope.cns.fr/spip/Vitis-vinifera-e.html. Gene intron/extron structure information was collected from the genome annotations of Populus and Vitis from NCBI and Phytozome http://www.phytozome.net databases.

\section{Conserved motifs analyses}

The program MEME http://meme.sdsc.edu[53] was used to identify motifs in the candidate Populus and Vitis OPT protein sequences. MEME was run locally with the following parameters: number of repetitions $=$ any, maximum number of motifs $=30$, and with optimum motif widths constrained to between 6 and 200 residues.

\section{Microarray analyses}

The genome-wide microarray data of Populus published by Dharmawardhana and coworkers [71] were obtained from the NCBI Gene Expression Omnibus (GEO) with Accession Numbers GSE13043 and GSE21481. Probe sets corresponding to the putative Populus OPTs were identified on website http://genome.jgi-psf.org/. The microarray data for Vitis reported by Lund and coworkers [72] and Fennell [73] were obtained from GEO with Accession Numbers GSE11406 and GSE17502, respectively. The Plant Expression Database (PLEXdb, http://www.plexdb.org/index.php) [74] was also used for expression analyses. For genes with more than one set of probes, the median of expression values were used. Finally, the expression data were gene-wise normalized and hierarchically clustered based on Pearson coefficients with average linkage in the Genesis (version 1.7.6) program [75].

\section{Functional divergence analyses}

To estimate the level of functional divergence and to predict amino acid residues responsible for functional differences in the OPT subfamilies, the coefficients of type-I functional divergence were calculated using the method suggested by $\mathrm{Gu}$ et al. [59,60]. The analyses were carried out with DINERGE (version 2.0). The method is based on maximum likelihood procedures to estimate significant changes in the site-specific shift of evolutionary rate or site-specific shift of amino acid properties after the emergence of two paralogous sequences. The advantage of this method is that it uses amino acid sequences and, therefore, is not sensitive to saturation of synonymous sites. Type-I functional divergence designates amino acid configurations that are highly conserved in gene 1 but highly variable in gene 2 , or vice versa, implying that these residues have experienced altered functional constraints [59]. Coefficients of functional divergence that are significantly greater than 0 indicate site-specific altered selective constraints or radical shifts of amino acid physiochemical properties after gene duplication. Site-specific posterior analysis was used to predict amino acid residues that were crucial for functional divergence [45].

\section{Positive selection assessment}

Identification of site-specific positive and purifying selection was calculated with the Selecton server http://selecton.tau.ac.il/, which uses a Bayesian inference approach for the evolutionary models $[61,76] . K_{a} /$ $K_{s}$ values are used to estimate the two types of substitutions events by calculating the synonymous rate $\left(K_{s}\right)$ and the non-synonymous rate $\left(K_{a}\right)$, at each codon site. The server implements several evolutionary models that describe in probabilistic terms how characters evolve. In this study, two of the evolutionary models (M8 and M7) were used. Each of the models uses different biological assumptions so that different 
hypotheses can be tested and the model that best fits the data can be selected. Briefly, M8 allows for positive selection operating on the protein. A proportion $\mathrm{p}_{0}$ of the sites are drawn from a beta distribution (defined in the interval 0 [1]), and a proportion $\mathrm{p}_{1}\left(=1-\mathrm{p}_{0}\right)$ of the sites are drawn from an additional category $\omega_{\mathrm{s}}$ (defined to be $\geq 1$ ). Thus, sites drawn from the beta distribution are sites experiencing purifying selection, whereas sites drawn from the $\omega_{\mathrm{s}}$ category are sites experiencing either neutral or positive selection. The M7 model is similar to M8, except that it assumes only a beta distribution with no additional category. Thus, it allows mainly for purifying selection in the protein. These models all assume a statistical distribution to account for heterogeneous $K_{a} / K_{s}$ values among sites. The distributions are approximated using eight discrete categories and the $K_{a} / K_{s}$ values are computed by calculating the expectation of the posterior distribution [61].

\section{Additional material}

Additional file 1: Figure S1. Microarray based expression profiles of rice OPT genes across a variety of tissue or organs. Expression of OPT genes during developmental stages are presented as scatterplot at

GENVESTIGATOR http://www.genevestigator.ethz.ch. The transcript levels are depicted by color scale representing log2 values. Red denotes high expression and green denotes low expression. OsYSL12 was not represented on the OS_51 K microarray.

Additional file 2: Table S1. Pairwise identities between homologous pairs of OPT genes from Vitis, Populus, Arabidopsis and rice. Pairwise identities and sequence alignments of the 16 homologous pairs identified from the four species OPTs.

Additional file 3: Figure S2. Chromosomal locations of the Arabidopsis OPT genes. The lines join the segmental duplicated homologous blocks.

Additional file 4: Figure S3. Chromosomal locations of the rice OPT genes. The lines join the segmental duplicated homologous blocks that are indicated using the same colors.

Additional file 5: Figure S4. Sequence logo and regular expression of the different motifs identified in the OPT gene family.

\section{Acknowledgements}

This project is partly supported by grants from the National Science Foundation of China (No. 30871704, and No.30971452) and the "100 Talents" Program of the Chinese Academy of Sciences to XH and from the National Science Foundation of China (No. 31100923) and Jiangsu University Senior Personnel Research Grants (10JDG027) to JC.

\section{Author details}

'Key Laboratory of Biodiversity and Biogeography, Kunming Institute of Botany, Institute of Tibet Plateau Research at Kunming, Chinese Academy of Sciences, Kunming, 650204, China. ${ }^{2}$ Institute of Life Sciences, Jiangsu University, Zhenjiang, Jiangsu, 212013, China. ${ }^{3}$ Department of Biology, East Carolina University, Greenville, NC, 27858, USA.

\section{Authors' contributions}

$J C$ carried out the computational analyses and wrote the in-house program. $\mathrm{JC}$ and $\mathrm{XH}$ interpreted the results and wrote the manuscript. JC and YY were involved in planning of experiments. $\mathrm{JH}$ performed phylogenetic analyses and participated manuscript writing. $\mathrm{XH}$ revised the final version of the manuscript and headed the project. All authors read and approved the final manuscript.

Received: 10 April 2011 Accepted: 26 September 2011

Published: 26 September 2011

\section{References}

1. Busch W, Saier MH Jr: The IUBMB-Endorsed transporter classification system. Mol Biotech 2002, 27(3):253-262.

2. Saier MH Jr, Yen MR, Noto K, Tamang DG, Elkan C: The Transporter Classification Database: recent advances. Nucleic Acids Res 2009, , 37 Database: D274-278.

3. Hauser M, Narita V, Donhardt AM, Naider F, Becker JM: Multiplicity and regulation of genes encoding peptide transporters in Saccharomyces cerevisiae. Mol Membr Biol 2001, 18(1):105-112.

4. Rea PA: Plant ATP-binding cassette transporters. Annu Rev Plant Biol 2007, 58:347-375.

5. Wang R, Liu D, Crawford NM: The Arabidopsis CHL1 protein plays a major role in high-affinity nitrate uptake. Proc Natl Acad Sci USA 1998, 95(25):15134-15139.

6. Chiang CS, Stacey G, Tsay YF: Mechanisms and functional properties of two peptide transporters, AtPTR2 and fPTR2. J Biol Chem 2004, 279(29):30150-30157.

7. Lubkowitz MA, Hauser L, Breslav M, Naider F, Becker JM: An oligopeptide transport gene from Candida albicans. Microbiol 1997, 143(Pt2):387-396.

8. Lubkowitz MA, Barnes D, Breslav M, Burchfield A, Naider F, Becker JM: Schizosaccharomyces pombe isp4 encodes a transporter representing a novel family of oligopeptide transporters. Mol Microbiol 1998, 28(4):729-741.

9. Curie C, Panaviene Z, Loulergue C, Dellaporta SL, Briat JF, Walker EL: Maize yellow stripe1 encodes a membrane protein directly involved in $\mathrm{Fe}$ (III) uptake. Nature 2001, 409(6818):346-349.

10. Roberts LA, Pierson AJ, Panavise Z, Walker EL: Yellow Stripe1 expanded roles for the Maize iron-phytosiderophore transporter. Plant Physiol 2004, 135(1):112-120.

11. DiDonato RJ Jr, Roberts LA, Sanderson T, Eisley RB, Walker EL: Arabidopsis Yellow Stripe-Like2 (YSL2): a metal-regulated gene encoding a plasma membrane transporter of nicotianamine-metal complexes. Plant J 2004, 39(3):403-414.

12. Koike S, Inoue H, Mizuno D, Takahashi M, Nakanishi H, Mori S, Nishizawa NK: OsYSL2 is a rice metal-nicotianamine transporter that is regulated by iron and expressed in the phloem. Plant J 2004, 39(3):415-424.

13. Murata Y, Ma JF, Yamaji F, Ueno D, Nomoto K, Iwashita T: A specific transporter for iron(III)-phytosiderophore in barley roots. Plant J 2006, 46(4):563-572.

14. Aoyama T, Kobayashi T, Takahashi M, Nagasaka S, Usuda K, Kakei Y, Ishimaru Y, Nakanishi H, Mori S, Nishizawa NK: OsYSL18 is a rice iron(III)deoxymugineic acid transporter specifically expressed in reproductive organs and phloem of lamina joints. Plant Mol Biol 2009, 70(6):681-692.

15. Lee S, Chiecko JC, Kim SA, Walker EL, Lee Y, Guerinot ML, An G: Disruption of OsYSL15 leads to iron inefficiency in rice plants. Plant Physiol 2009, 150(2):786-800.

16. Ishimaru Y, Masuda H, Bashir K, Inoue H, Tsukamoto T, Takahashi M, Nakanishi H, Aoki N, Hirose T, Ohsugi R, Nishizawa NK: Rice metalnicotianamine transporter, OsYSL2, is required for the long-distance transport of iron and manganese. Plant $J$ 2010, 62(3):379-390.

17. Stacey MG, Patel A, McClain WE, Mathieu M, Remley M, Rogers EE, Gassmann W, Blevins DG, Stacey G: The Arabidopsis AtOPT3 protein functions in metal homeostasis and movement of iron to developing seeds. Plant Physiol 2008, 146(2):589-601.

18. Koh S, Wiles AM, Sharp JS, Naider FR, Becker JM, Stacey G: An oligopeptide transporter gene family in Arabidopsis. Plant Physiol 2002, 128(1):21-29.

19. Cagnac O, Bourbouloux A, Chakrabarty D, Zhang MY, Delrot S: AtOPT6 transports glutathione derivatives and is induced by primisulfuron. Plant Physiol 2004, 135(3):1378-1387.

20. Stacey MG, Osawa H, Patel A, Gassmann W, Stacey G: Expression analyses of Arabidopsis oligopeptide transporters during seed germination, vegetative growth and reproduction. Planta 2006, 223(2):291-305.

21. Pike S, Patel A, Stacey G, Gassmann W: Arabidopsis OPT6 is an oligopeptide transporter with exceptionally broad substrate specificity. Plant Cell Physiol 2009, 50(11):1923-1932. 
22. Bogs J, Bourbouloux A, Cagnac O, Wachter A, Rausch T, Delrot S: Functional characterization and expression analysis of a glutathione transporter, BjGT1, from Brassica juncea: evidence for regulation by heavy metal exposure. Plant Cell Environ 2003, 26(10):1703-1711.

23. Vasconcelos MW, Li GW, Lubkowitz MA, Grusak MA: Characterization of the PT clade of oligopeptide transporters in rice. The Plant Genome 2008, 1(2):77-88.

24. Zhang MY, Bourbouloux A, Cagnac O, Srikanth CV, Rentsch D, Bachhawat AK, Delrot S: A novel family of transporters mediating the transport of glutathione derivatives in plants. Plant Physiol 2004, 134(1):482-491

25. Lubkowitz M: The Oligopeptide Transporters: A Small Gene Family with a Diverse Group of Substrates and Functions? Mol Plant 2011, 4(3):407-415.

26. Gomolplitinant KM, Saier MH Jr: Evolution of the oligopeptide transporter family. J Membr Biol 2011, 240(2):89-110.

27. Marchler-Bauer A, Anderson JB, Chitsaz F, Derbyshire MK, DeWeese-Scott C, Fong JH, Geer LY, Geer RC, Gonzales NR, Gwadz M, He S, Hurwitz DI, Jackson JD, Ke Z, Lanczycki CJ, Liebert CA, Liu C, Lu F, Lu S, Marchler GH, Mullokandov M, Song JS, Tasneem A, Thanki N, Yamashita RA, Zhang D, Zhang N, Bryant SH: CDD: specific functional annotation with the Conserved Domain Database. Nucleic Acids Res 2009, 37 Database: D205-210.

28. Marchler-Bauer A, Lu S, Anderson JB, Chitsaz F, Derbyshire MK, DeWeeseScott C, Fong JH, Geer LY, Geer RC, Gonzales NR, Gwadz M, Hurwitz Dl, Jackson JD, Ke Z, Lanczycki CJ, Lu F, Marchler GH, Mullokandov M, Omelchenko MV, Robertson CL, Song JS, Thanki N, Yamashita RA, Zhang D, Zhang N, Zheng C, Bryant SH: CDD: a Conserved Domain Database for the functional annotation of proteins. Nucleic Acids Res 2011, , 39 Database: D225-229.

29. Guindon S, Gascuel O: A simple, fast, and accurate algorithm to estimate large phylogenies by maximum likelihood. Syst Biol 2003, 52:696-704.

30. Lartillot N, Lepage T, Blanquart S: PhyloBayes 3: a Bayesian software package for phylogenetic reconstruction and molecular dating. Bioinformatics 2009, 25:2286-2288.

31. Hu R, Qi G, Kong Y, Kong D, Gao Q, Zhou G: Comprehensive analysis of NAC domain transcription factor gene family in Populus trichocarpa. BMC Plant Biol 2010, 10:145

32. Afoufa-Bastien D, Medici $A$, Jeauffre J, Coutos-Thévenot $P$, Lemoine $R$, Atanassova R, Laloi M: The Vitis vinifera sugar transporter gene family: phylogenetic overview and macroarray expression profiling. BMC Plant Biol 2010, 10:245.

33. Le Jean M, Schikora A, Mari S, Briat JF, Curie C: A loss-of-function mutation in AtYSL1 reveals its role in iron and nicotianamine seed loading. Plant J 2005, 44(5):769-782.

34. Waters BM, Chu HH, Didonato RJ, Roberts LA, Eisley RB, Lahner B, Salt DE, Walker EL: Mutations in Arabidopsis yellow stripe-like1 and yellow stripelike3 reveal their roles in metal ion homeostasis and loading of metal ions in seeds. Plant Physiol 2006, 141(4):1446-1458.

35. Chu HH, Chiecko J, Punshon T, Lanzirotti A, Lahner B, Salt DE, Walker EL: Successful reproduction requires the function of Arabidopsis Yellow Stripe-Like1 and Yellow Stripe-Like3 metal-nicotianamine transporters in both vegetative and reproductive structures. Plant Physiol 2010, 154(1):197-210.

36. Zimmermann $P$, Hirsch-Hoffmann M, Hennig L, Gruissem W: GENEVESTIGATOR. Arabidopsis microarray database and analysis toolbox. Plant Physiol 2004, 136(1):2621-2632.

37. Sterck L, Rombauts S, Jansson S, Sterky F, Rouze P, Van de Peer Y: EST data suggest that poplar is an ancient polyploid. New Phytol 2005, 67(1):165-170.

38. Wolfe KH, Gouy M, Yang YW, Sharp PM, Li WH: Date of the monocot-dicot divergence estimated from chloroplast DNA sequence data. Proc Natl Acad Sci USA 1989, 86(16):6201-6205.

39. Crane PR, Friis EM, Pedersen KR: The origin and early diversification of angiosperms. Nature 1995, 374(6517):27-33.

40. Kellogg EA: Evolutionary history of the grasses. Plant Physiol 2001, 125(3):1198-1205.

41. Jaillon O, Aury J-M, Noel B, Policrit A, Clepet C, Casagrande A, Choisne N, Aubourg C, Vitulo N, Jubin C, et al: The grapevine genome sequence suggests ancestral hexaploidization in major angiosperm phyla. Nature 2007, 449(7161):463-467
42. Hardison RC: A brief history of hemoglobins: plant, animal, protist, and bacteria. Proc Natl Acad Sci USA 1996, 93(12):5675-5679.

43. Lin H, Zhu W, Silva JC, Gu X, Buell CR: (2006) Intron gain and loss in segmentally duplicated genes in rice. Genome Biol 2006, 7(5):R41.

44. Cao J, Shi F, Liu X, Huang G, Zhou M: Phylogenetic analysis and evolution of aromatic amino acid hydroxylase. FEBS Lett 2010, 584(23):4775-4782.

45. Li W, Liu B, Yu L, Feng D, Wang H, Wang J: Phylogenetic analysis, structural evolution and functional divergence of the 12-oxophytodienoate acid reductase gene family in plants. BMC Evol Biol 2009, 9:90.

46. Cao J, Shi F, Liu X, Jia J, Zeng J, Huang G: Genome-wide identification and evolutionary analysis of Arabidopsis Sm genes family. J Biomol Struct Dyn 2011, 28(4):535-544.

47. Kent WJ, Baertsch R, Hinrichs A, Miller W, Haussler D: Evolution's cauldron: duplication, deletion, and rearrangement in the mouse and human genomes. Proc Natl Acad Sci USA 2003, 100(20):11484-11489.

48. Mehan MR, Freimer NB, Ophoff RA: A genome-wide survey of segmental duplications that mediate common human genetic variation of chromosomal architecture. Hum Genomics 2004, 1(5):335-344.

49. Tuskan GA, Difazio S, Jansson S, Bohlmann J, Grigoriev I, Hellsten U, Putnam N, Ralph S, Rombauts S, Salamov A, et al: The genome of black cottonwood, Populus trichocarpa (Torr. \& Gray). Science 2006, 313(5793):1596-1604

50. Licausi F, Giorgi FM, Zenoni S, Osti F, Pezzotti M, Perata P: Genomic and transcriptomic analysis of the AP2/ERF superfamily in Vitis vinifera. BMC Genomics 2010, 11:719.

51. Blanc G, Hokamp K, Wolfe KH: A recent polyploidy superimposed on older large-scale duplications in the Arabidopsis genome. Genome Res 2003, 13(2):137-144.

52. Guyot R, Keller B: Ancestral genome duplication in rice. Genome 2004, 47(3):610-614.

53. Bailey TL, Williams N, Misleh C, Li WW: MEME: discovering and analyzing DNA and protein sequence motifs. Nucleic Acids Res 2006, , 34 Web Server: W369-373.

54. Prince VE, Picket FB: Splitting pairs: the diverging fates of duplicated genes. Nat Rev Genet 2002, 3(11):827-837.

55. Blanc $\mathrm{G}$, Wolfe $\mathrm{KH}$ : Functional divergence of duplicated genes formed by polyploidy during Arabidopsis evolution. Plant Cell 2004, 16(7):1679-1691.

56. Deluc LG, Grimplet J, Wheatley MD, Tillett RL, Quilici DR, Osborne C, Schooley DA, Schlauch KA, Cushman JC, Cramer GR: Transcriptomic and metabolite analyses of Cabernet Sauvignon grape berry development. BMC Genomics 2007, 8:429.

57. Deluc LG, Quilici DR, Decendit A, Grimplet J, Wheatley MD, Schlauch KA, Mérillon JM, Cushman JC, Cramer GR: Water deficit alters differentially metabolic pathways affecting important flavor and quality traits in grape berries of Cabernet Sauvignon and Chardonnay. BMC Genomics 2009, 10:212.

58. Cramer GR, Ergül A, Grimplet J, Tillett RL, Tattersall EA, Bohlman MC, Vincent D, Sonderegger J, Evans J, Osborne C, Quilici D, Schlauch KA, Schooley DA, Cushman JC: Water and salinity stress in grapevines: early and late changes in transcript and metabolite profiles. Funct Integr Genomics 2007, 7(2):111-34.

59. Gu X: Statistical methods for testing functional divergence after gene duplication. Mol Biol Evol 1999, 16(12):1664-1674.

60. Gu X: (2001) Maximum-likelihood approach for gene family evolution under functional divergence. Mol Biol Evol 2001, 18(4):453-464.

61. Stern A, Doron-Faigenboim A, Erez E, Martz E, Bacharach E, Pupko T: Selecton 2007: advanced models for detecting positive and purifying selection using a Bayesian inference approach. Nucleic Acids Res 2007, , 35 Web Server: W506-511.

62. Horton P, Park KJ, Obayashi T, Fujita N, Harada H, Adams-Collier CJ, Nakai K. WoLF PSORT: protein localization predictor. Nucleic Acids Res 2007, , 35 Web Server: W585-587.

63. Edgar RC: MUSCLE: multiple sequence alignment with high accuracy and high throughput. Nucleic Acids Res 2004, 32(5):1792-1797.

64. Keane TM, Creevey CJ, Pentony MM, Naughton TJ, McLnerney JO: Assessment of methods for amino acid matrix selection and their use on empirical data shows that ad hoc assumptions for choice of matrix are not justified. BMC Evol Biol 2006, 6:29.

65. Le SQ, Gascuel O: An improved general amino acid replacement matrix. Mol Biol Evol 2008, 25:1307-1320. 
66. Tamura K, Peterson D, Peterson N, Stecher G, Nei M, Kumar S: MEGA5: Molecular Evolutionary Genetics Analysis using Maximum Likelihood, EvolutionaryDistance, and Maximum Parsimony Methods. Mol Biol Evol 2011.

67. Comeron JM: K-Estimator: calculation of the number of nucleotide substitutions per site and the confidence intervals. Bioinformatics 1999, 15(9):763-764

68. Yu J, Wang J, Lin W, Li S, Li H, Zhou J, Ni P, Dong W, Hu S, Zeng C, et al: The Genomes of Oryza sativa: a history of duplications. PLOS Biol 2005, 3(2):e38.

69. Lynch $\mathrm{M}$, Conery JS: The evolutionary fate and consequences of duplicate genes. Science 2000, 290(5494):1151-1155.

70. Gaut BS, Morton BR, McCaig BC, Clegg MT: Substitution rate comparisons between grasses and palms: synonymous rate differences at the nuclear gene Adh parallel rate differences at the plastid gene rbcL. Proc Natl Acad Sci USA 1996, 93(19):10274-10279.

71. Dharmawardhana P, Brunner AM, Strauss SH: Genome-wide transcriptome analysis of the transition from primary to secondary stem development in Populus trichocarpa. BMC Genomics 2010, 11:150.

72. Lund ST, Peng FY, Nayar T, Reid KE, Schlosser J: Gene expression analyses in individual grape (Vitis vinifera L.) berries during ripening initiation reveal that pigmentation intensity is a valid indicator of developmental staging within the cluster. Plant Mol Biol 2008, 68(3):301-315.

73. Sreekantan L, Mathiason K, Grimplet J, Schlauch K, Dickerson JA, Fennell AY: Differential floral development and gene expression in grapevines during long and short photoperiods suggests a role for floral genes in dormancy transitioning. Plant Mol Biol 2010, 73(1-2):191-205.

74. Wise RP, Caldo RA, Hong L, Shen L, Cannon EK, Dickerson JA: In Plant Bioinformatics-Methods and Protocols. In Methods in Molecular Biology. Volume 406. Edited by: Edwards D. Humana Press, Totowa, NJ; 2007:347-363.

75. Sturn A, Quackenbush J, Trajanoski Z: Genesis: cluster analysis of microarray data. Bioinformatics 2002, 18(1):207-208.

76. Doron-Faigenboim A, Stern A, Mayrose I, Bacharach E, Pupko T: Selecton: a server for detecting evolutionary forces at a single amino-acid site. Bioinformatics 2005, 21(9):2101-2103.

77. Hirokawa T, Boon-Chieng S, Mitaku S: SOSUI: classification and secondary structure prediction system for membrane proteins. Bioinformatics 1998, 14(4):378-379.

doi:10.1186/1471-2164-12-465

Cite this article as: Cao et al:: Analyses of the oligopeptide transporter gene family in poplar and grape. BMC Genomics 2011 12:465.

\section{Submit your next manuscript to BioMed Central and take full advantage of:}

- Convenient online submission

- Thorough peer review

- No space constraints or color figure charges

- Immediate publication on acceptance

- Inclusion in PubMed, CAS, Scopus and Google Scholar

- Research which is freely available for redistribution

Submit your manuscript at www.biomedcentral.com/submit
Biomed Central 